\title{
Interviewing Baltimore Older Adults About Food System Change: Oral History as a Teaching Tool
}

Roni A. Neff, Linnea I. Laestadius, Susan DiMauro, and Anne M. Palmer

\begin{abstract}
Urban food systems have changed considerably over the past half century. Older adults' descriptions of place-based, personal food system history can help inform student learning and may contribute to expert understanding of food system change. Structural and social shifts in food purchasing and consumption contribute to diet-related disease and loss of historical food cultures in cities. Modern efforts to improve food systems are rarely informed by history, despite the potential benefits. Students performed oral history interviews with Baltimore older adults. Transcripts were analyzed using an inductive grounded theory approach. Interviewees described a shift from food they perceived as natural and healthy to food seen as lacking freshness, with additives and poor flavor. Many mistrusted the food industry including retailers. Some emphasized benefits of modern changes such as reduced preparation time. Despite low incomes, interviewee concerns went well beyond food prices. We describe and reflect on insights from the oral histories, while presenting a case study of the use of oral history in graduate education. To our knowledge, this is the first paper describing oral history with older adults focused on the food system.
\end{abstract}

\section{Keywords}

History, Food culture, Qualitative interviews, Student project

\section{Introduction}

Older adults have a historic vantage point on social, economic, and environmental changes. Engaging with this population can offer valuable perspectives for students and researchers. Today's older adults have witnessed dramatic shifts in the food system (the system encompassing all aspects of producing, distributing and consuming food, everything that shapes those processes and that results from them, and all of the related relationships). Since 1950, the food system has grown increasingly industrialized, with larger and more globalized food businesses and fewer small farms (McLaughlin \& Gomez, 2015). Options for consumer convenience have expanded, and many processed foods are now formulated to meet flavor, shelf life, and food safety goals (Cavender, 2015). Americans spend a far lower share of disposable income on food than they did 50 to 100 years ago (USDA ERS, 2016), though the food prices are much higher (Church \& Stewart, 2013). Social changes over the past half-century, including changes in population dynamics, urbanization, women in the workplace, and level of parental influence over what children eat, have profoundly affected our diets. 
Over the lifetimes of today's older adults, urban environments have also changed greatly. In 1970, Baltimore, Maryland had nearly one million residents. Today Baltimore's population is around 620,000, following decades of declining jobs in heavy industry, increased job opportunities in the suburbs, and demographic movement toward suburbs facilitated by car ownership and transportation networks (U.S. Bureau of the Census, 2014, 1995). The city's postWWII racial composition also shifted significantly, as African Americans migrated to Baltimore from rural areas in the Carolinas and elsewhere in the South as part of the Great Migration. Meanwhile, redlining and fear caused many whites and later, middle class Blacks to leave the city (Pietila, 2010). Today Baltimore is 63\% African American (U.S. Bureau of the Census, 2014). As industrial jobs disappeared, poverty increased, bringing with it social challenges.

As in other urban centers, many Baltimore supermarkets had closed or moved to suburban areas by the 1980s, due to factors including the need for more land to support larger stores and parking lots, reduced profit margins in urban areas, crime, and perceptions of crime (Eisenhauer, 2001). This loss of supermarkets reduced access to fresh, healthy food. While Baltimore still has many small stores, their characteristics have changed. Historically, such stores tended to specialize in fresh foods like produce, baked goods, or meats, whereas today they provide mostly processed and convenience snack foods.

Such changes have resulted in an urban food environment, both in Baltimore and nationally, characterized by limited fresh food access and high prices. These changes constrain opportunities to eat healthfully for many urban, low income residents, particularly those with low access to transportation and limited mobility (Gittelsohn et al., 2008; Morland, Wing, \& Diez Roux, 2002). Today $25 \%$ of the city's population lives in areas characterized as food deserts (Buzcynski, Freishtat, \& Buzogany, 2015). Despite these challenges, multiple studies suggest that low-income older adults are interested in eating fruits and vegetables, particularly farm-fresh produce. They also tend to make good use of services that make healthy food affordable and accessible, such as farmers market coupons and mobile produce trucks (Kunkel, Luccia, \& Moore, 2003; Johnson, Beaudoin, Smith, Beresford, \& LoGerfo, 2004; Smith, Johnson, Beaudoin, Monsen, \& LoGerfo 2004; Abusabha, Namjoshi, \& Klein, 2011; Middleton \& Smith, 2011). Older adults, therefore, may represent valuable allies, partners, and a resource for food system change.

\section{Oral History in Graduate Education}

Adults aged 65 or older are the fastest growing segment of the U.S. population; by 2030, they will constitute about 19\% of the population (Song, Simon, \& Patel, 2014). Much can be learned from their insights about the past and present, and their thoughts as to what should be prioritized, moving forward. Oral history is one approach to gathering this information. The Oral History Association defines oral history as "a field of study and a method of gathering, preserving and interpreting the voices and memories of people, communities, and participants in past events" (Oral History Association, n.d.). This method has been used in education from primary through graduate levels (Sitton, Mehaffy, \& Davis, 1983; Oral History Association, 2009; Ritchie, 2015; Donald \& Tribbey, 2002). 
The oral history project we describe was performed in each of three years as part of the Johns Hopkins Bloomberg School of Public Health graduate course, Baltimore Food Systems: A Case Study in Urban Food Environments, taught by Roni Neff and Anne Palmer at the time of data collection. This community-engaged eight-week seminar course included field trips to a supermarket, emergency food provider, urban farm, and peri-urban farm, and featured guest speakers from throughout the city food system. To further ground the students' understanding, many of the readings presented qualitative research and other documents providing in-depth insights on food systems. For their mid-term assignment, students performed oral history interviews with low-income older adults in East Baltimore to learn how this population perceives changes in the food system and to better understand what members of these older generations see as the most significant challenges and opportunities for change in today's food system. The findings were so compelling that after the first year we sought IRB approval to make the assignment part of a formal research study, which was performed from 2010-12.

This study addressed the following research questions: (a) How do interviewees perceive today's food system? (b) How do they describe changes in food and the food system since their childhoods? (c) How are their current dietary attitudes and behaviors rooted in past experiences? And (d) What do they see as top priorities for food system change in Baltimore?

Our goal in this paper is to share insights from older adults' comments about food and related cultural issues, and to discuss oral history as a pedagogical tool. Future analyses will examine their comments on food access and procurement.

\section{Methods}

Student Assignment and Training

Data collection took place during the aforementioned eight-week course annually from 2010-12. Students received training in oral history interviewing, performed readings on the method, and practiced with each other in class. A number had taken additional coursework on qualitative methods. The students received training in research protocols and ethics for working with human subjects, and completed the Collaborative Institutional Training Initiative (CITI) training module on human-subjects research. The assignment protocol detailed steps as described below.

Subjects

Course faculty established a relationship with a nearby residential senior center. The center provides one- or two-bedroom apartments to persons aged 62 or older with a maximum income of $\$ 30,000$ for one person or $\$ 34,250$ for two people. Apartments have fully equipped kitchens, enabling meal preparation. The center is located in a Baltimore neighborhood that in 2011 was 87\% African American with a median household income of \$18,522 (Baltimore City Health Department [BCHD], 2011). The neighborhood was classified as a food desert, with relatively low access to fresh foods and high access to energy-dense foods (The Johns Hopkins Center for a Livable Future, 2012). In 2011, it had a fast-food density of 10.9 restaurants per 10,000 residents (more than 4.5 times the city's fast-food density); a carryout-restaurant density of 34.9 per 10,000 (nearly three times that of the city); and a corner-store density of 10.9 per 10,000 (just 
over the city's density of 9.0 per 10,000). Based on active transportation time for able-bodied adults, the nearest supermarket was 14 minutes away by foot - an important measure because 60 percent of residents in the area lack vehicles (BCHD, 2011). Heart disease and cancer rates were also above the city's already-high rates (BCHD, 2011). Many interviewees had lived in the immediate area before moving into this residence, while others had lived elsewhere in Baltimore.

Participants had to be at least 65 and lived in the Baltimore, MD area for at least 25 years. Recruitment was performed annually from $2010-12$ by a staff contact who publicized the project and the opportunity for residents to sign up for interview time slots. The contact screened out individuals who might have difficulty completing the interview due to physical or mental health problems or English language competency. The contact also reserved a room where interviews could be conducted privately.

\section{Data Collection and Student Data Analysis Procedures}

Student investigator pairs conducted semi-structured 40-60 minute interviews exploring topics including food-related beliefs, preferences, behaviors, cultural influences, and food access and availability. The instructors sought ideas for additional questions from the class each year, but the guide remained similar. Table 1 provides sample questions. Student investigators were encouraged to follow the flow of the conversation so long as it remained generally on-topic, and to provide follow-up probes to elicit details. They were instructed to avoid personal questions, topics likely to cause discomfort, and information that could be deemed confidential. A teaching assistant or the instructor was available during all interview time slots in case a problem arose.

Table 1

\section{Sample Interview Questions}

\begin{tabular}{|l|}
\hline What kinds of foods did you eat when you were younger? \\
\hline How have your/your family's diets changed over the years? \\
\hline How much time did you/your family spend on food preparation in the past? \\
\hline Where did you get the food that you ate when you were younger? \\
\hline Did you have a garden? \\
\hline What is good/bad about the food environment now? \\
\hline What do you think is needed to improve today's food environment? \\
\hline
\end{tabular}

Student investigators audio-recorded and transcribed the interviews verbatim. Individual identifiers were not collected. We obtained oral consent from all participants. Each participant received a $\$ 25$ gift card. We maintained confidentiality by asking the site contact to assign interviewees anonymous codes, and placed these on sealed envelopes. The Johns Hopkins Bloomberg School of Public Health Institutional Review Board (IRB) classified the project as exempt (Protection of Human Subjects, 2016). In 2011 and 2012, we received IRB approval to share interview transcripts with interviewees as a keepsake, and most took advantage of this option. 
Students summarized the interviews in five-page papers and five-minute in-class presentations. In both, students were encouraged to (a) focus on the material they found most interesting; (b) focus on that which their interviewees chose to focus most; and (c) to include direct quotes wherever possible. Each also provided a half-page (and single-slide) reflection on insights from the interviews. The current analysis used only the interview transcripts rather than these student summaries.

\section{Current Study Data Analysis Procedures}

Interview transcripts were coded by instructors and two research assistants using an inductive grounded theory approach. This approach identifies broad thematic categories that emerge from data through a rigorous and iterative process of initial and focused coding (Charmaz, 2006). Three transcripts were selected for independent initial line-by-line coding by all authors. Initial codes were used to develop a preliminary coding scheme consisting of focused codes organized into thematic categories. Four additional transcripts were then coded independently by all authors to ensure consensus and consistent application of the coding scheme. Definitions and exclusion/inclusion criteria were developed for each focused code. After discussion and additional refinement of the coding scheme, each transcript was coded independently by two authors. Pairs met to discuss their coding and address any inconsistent coding decisions. Throughout the coding process, the coding scheme evolved as new codes emerged from the data and existing codes and themes were further refined. Transcripts were re-coded as necessary to reflect these changes. All coding was conducted using ATLAS.ti (Scientific Software Development GmbH, Berlin, Germany).

\section{Findings}

Twenty-six interviews were performed with older adults living in East Baltimore in the spring semesters of 2010, 2011, and 2012. Two transcripts were omitted for audio-recording problems or administrative reasons, leaving 24 for analysis. Interviewee ages ranged from 65 to about 86 at time of interview, with a mean of about 72 (meaning they were born during the mid-1920s through 1947). Nine interviewees had lived in Baltimore their entire lives, and five had arrived in the 1940s to 1950s. Others had lived in Baltimore intermittently or full data on residential history were not collected. Some interviewees suffered from health conditions including asthma, allergies, broken hip, diabetes, or hypertension. Most were female and African American.

Interviewees described many changes in the food system between their childhoods and today. Overall they thought that the quality of the food system had declined. The changes they discussed fall into four categories: a) Valuing the flavor and tradition of fresh foods; b) Concerns about flavors and risks introduced by food additives and processing; c) Changing food preparation habits; d) Limited interest in food origins and limited trust in the modern food system. In addition, (e) participants described their top priorities for food system change.

Valuing the Flavor and Tradition of Fresh Foods

Nineteen of 24 interviewees described a reduction in food freshness, and many considered this to be the biggest change in food between their childhoods and today. Many said they preferred the 
taste of fresh foods, particularly foods coming directly from farms or gardens. Most thought that food today in general did not taste as good as it had in their childhoods:

You can really tell the difference. Back then the food was good; it was natural. Now, like I said with all this food and stuff, that's frozen ... It just doesn't have the same taste to me. (Interview \#6)

Everything has changed! See ya'll don't know anything about that 'cause you're coming up in this era so you gotta take what you can get. See back in our day everything it was much, much better. The food tasted better, you know? (\#25)

Beyond inferior taste, many felt that less-than-fresh or canned food had reduced nutritional value, though they generally did not mention specific nutritional changes of concern: "They should take some of the things they put in the cans, out of the cans. Because I think when they put it in the cans, they're losing something. The protein or the nutrients or something." (\#13)

Many interviewees spoke appreciatively and nostalgically of food produced on farms or gardens. Twelve indicated they or their families had farms or gardens during their childhoods, while three currently had gardens. Some urban-dwellers spent childhood summers with rural relatives. For several interviewees, farms or gardens were the primary or nearly only food source in childhood. Some also described fishing and hunting as providing significant food in the past and/or as being regular pastimes then. Those who had these experiences commonly emphasized they saw rural fresh food as preferable to foods purchased in urban areas. For example:

In the country the fruit was fresh fruit, because it's raised out-you could go look out and look at the trees and see apples, grapes, peaches, pears, and - fruit is better in the country than in the city, because it's fresh. (\#7)

Interviewees also commonly contrasted meats purchased and consumed during their childhoods with today's pre-packaged meats. In addition to those whose families purchased meats from nearby butchers, many recalled a shopping area where their families selected live chickens that were slaughtered on the spot. Others had observed animal slaughter in rural areas. Most valued the freshness of these meats, with one describing it as "an altogether different taste than the chicken that you buy in the store" (\#20). At least one described it, however, as "almost too fresh; I rather like the one that come from the market, already cured.” (\#25)

Many noted their families had intentionally sought out fresh foods and described going out of their way to obtain food fresher than the norm even at that time, whether from the docks, public markets, gardens, transported by rural relatives or other sources. Many of their families engaged in home food preservation in their childhoods, and interestingly, they generally associated these foods with freshness rather than categorizing them as canned or frozen: "We didn't have frozen foods back then, you know, everything was fresh ... She [interviewee's grandmother] would can string beans, tomatoes, corn, okra, whatever." (\#6)

Despite frequent negative remarks about industrially preserved foods, many interviewees indicated that they currently used their freezers for food preservation, particularly to enable them 
to have the foods they wanted, of the quality they wanted, between shopping trips. Some also appreciated canned and/or frozen foods for their relatively low prices and convenience:

There's a whole lot of things that cost a whole lot. Except for cans. I like canned goods. I like the fruits they have now. I can go to the Dollar Tree and buy canned foods for $\$ 1$ a can. (\#9)

Concerns about Flavors and Risks Introduced by Food Additives and Processing

The second-most frequently raised issue, discussed by 14 of 24 interviewees, was the increased use of additives and chemicals in both food production and processing, contrasted with what were sometimes referred to as "natural" foods. Many went on at some length on the topic and repeatedly returned to the theme, and five interviewees identified additives as the aspect of today's food system that they would most like to see changed. Most commonly, interviewees referred generically to "chemicals" or did not name the additive of concern. For example:

Like with the Purdue chicken I just bought, they say it's no additives in it, a whole lot of stuff is not in it. They tell you on the package what has not been given to the chickens.

So, I love me some chicken. (\#24)

The most commonly specified additive was sodium, followed by hormones and growth promoters, preservatives, injections, grease, and pesticides. Often interviewees validated their statements by indicating that others too spoke of these issues. In discussing their perceptions of changed food flavor, interviewees frequently singled out meats. They generally did not specify the types of changes they experienced, though one did say meat today was more "chalky" and "crumbly," and not as juicy as it had been in the past (\#6). Another described it as "gritty" (\#26).

An underlying theme in discussing additives was mistrust of food producers and manufacturers, although this was not always articulated directly. For example, one noted, "You don't know what those people have put in [food]" (\#24) and another explained, "I don't know what chemicals they're putting in the ground or in the hot house." (\#6) In most cases the implication was of using additives to increase profits for producers or manufacturers, regardless of consumer impacts. About half of those mentioning additives discussed their effect on flavor, commonly implying the perceived change in flavor was an indicator something was not right with the food item itself, not just a source of personal displeasure: "And I bet you ask any person around their 60 s or 70 s and they will say the same thing. It's a difference in the taste now. It's maybe something they do to it." (\#25)

Despite displeasure with the flavors many associated with additives, there were also a few comments indicating that interviewees enjoyed processed foods high in additives, but avoided them for health reasons - for example, "I haven't stopped eating the junk altogether, but I just try not to overdo it." (\#19) In particular, multiple interviewees indicated or implied they saw processed foods as unhealthy due to sodium and/or fat content.

Many were also concerned about health impacts from additives used in food production, although most expressed generic concerns. A few specifically mentioned hormone disruption, though not necessarily by name: "The girls is looking like women...They coming out, they developing fast and everything." (\#8) 
In some cases, statements about current additive use seem to be rooted in direct childhood farm work knowledge contrasted with perceptions of today's farm production methods:

The food back then had to be healthier, because these days they put all this stuff in them and feeding them, back then they gave them stuff that was good for them to make them better. But these days they put stuff in the food that makes a baby chicken into a chicken in three months. Now everything is strange, the food. Think about it. Everything is growing fast, the vegetables, the fruit. Used to take longer than a day to grow things and took a lot of work. Now they have machines, back then it was just our hands. (\#20)

Surprisingly, given this interest in food produced without additives, few interviewees mentioned organic foods. One implied that organic food was desirable, but that the price is "so high you can't afford it" (\#6). Table 2 summarizes concerns about additives across interviewees.

Table 2

Reported Concerns about Food Additives

\begin{tabular}{|c|c|c|}
\hline Category & Concern & $\begin{array}{l}\text { Perceived Reason for } \\
\text { Use }\end{array}$ \\
\hline $\begin{array}{l}\text { "Chemicals" and other } \\
\text { generic additives } \\
\text { (14 comments) }\end{array}$ & $\begin{array}{l}\text { - Health problems including high blood } \\
\text { pressure and children "act[ing] crazy" } \\
\text { - Poor taste, different taste } \\
\text { - Fast plant/animal growth rates }\end{array}$ & $\begin{array}{l}\text { - Profit for producers } \\
\text { - Lack of oversight } \\
\text { - Healthfulness } \\
\text { - Faster cultivation } \\
\end{array}$ \\
\hline Salt (11) & $\begin{array}{l}\text { - Salt is hidden (need to check labels) } \\
\text { - Unhealthy (high blood pressure, short term } \\
\text { physical symptoms, not medically permissible) }\end{array}$ & \\
\hline $\begin{array}{l}\text { Hormones, growth } \\
\text { promoters }(7)\end{array}$ & $\begin{array}{l}\text { - Unnatural effects on food } \\
\text { - Unhealthy } \\
\text { - Different taste } \\
\text { - Premature female development } \\
\end{array}$ & $\begin{array}{l}\text { - Poultry size } \\
\text { - Faster animal growth } \\
\text { - Faster production }\end{array}$ \\
\hline Fat, grease (6) & $\begin{array}{l}\text { - Affects preexisting health conditions } \\
\text { - Unhealthy } \\
\text { - "Clogs up" arteries }\end{array}$ & - Good taste \\
\hline Preservatives (5) & - Poor taste, different taste & \\
\hline Injections (4) & - Poor taste, different taste & $\begin{array}{l}\text { - To get it to market } \\
\text { - "Purify" food items }\end{array}$ \\
\hline
\end{tabular}

Changing Food Preparation Habits

Interviewees frequently commented on changes in dietary patterns since their childhoods, with emphasis on today's consumption of processed and prepared foods, and on the decline in cooking. Nostalgia for their mothers' cooking was frequently couched in terms of healthfulness. 
When praising the healthfulness of their childhood foods, no interviewee commented on fat and salt in traditional Southern cooking (though a few did mention this in context of foods others prepared for current social gatherings). Generally, the interviewees seemed to be saying their mothers had done nutrition, cooking, and shopping the "right" way: "Well my mother did all the cooking. Nothing like mother's cooking. She always made sure it was nutritious and had the food groups." (\#15)

Several discussed the substantial time their female relatives had invested in food preparation. With perceptions of this time-intensive and healthful cooking style as a baseline, many criticized today's mothers for not cooking as they and their forebears had, for their lack of cooking skills, for being "lazy," and for not providing healthy food to their children: "Lot of them lazy today now too. Nobody cooking every day, they ... what they like, their chicken boxes, chicken and French fries, and children are happy. And that's fried, all that grease and all.” (\#22)

Several also acknowledged the challenges faced by modern families and expressed sympathy for this generation not having the opportunity to experience home cooked meals. For example, one stated, "Because their parents are working and don't have a lot of time-they buy fast food, get prefixed snacks, personal pizzas ... I see that as people missing out on lots of things, like the old down-home recipes." (\#5) Another said, "People are out of jobs, not having money to feed the family. It has been a rough road if you do not know how to cook from scratch and buy all the stuff." (\#3) Many interviewees also recognized that changes over time, including the increased number of women in the workplace, had strengthened the value of speed and convenience:

Women are working now. Back when I was a younger girl, most women didn't work, they were home raising their children. Well, things got so that the incomes needed mom and pop to work so then mother was gone out to work then the older sister started preparing the food, or ... [bought meals, or] ate later. Everything has changed, it's changing every day. (\#22)

Finally, despite the judgments expressed about eating convenience foods and despite their general preferences for fresh food, interviewees varied greatly in their own consumption of processed and prepared food. Some said they preferred to make their own meals due to health, flavor, or habit. Others avoided cooking because they thought they were not effective cooks. Many who indicated they consumed convenience food provided motivations that highlighted the mobility, financial, and health challenges faced by older adults. One expressed relief at not having to cook and noted: "Now, I have gotten a little older and I don't feel like standing over that sink cutting up greens and washing them, that takes up a lot of time." (\#24) Another interviewee noted as a benefit of processed food that some could be purchased in measured portion sizes that were helpful in controlling food intake and avoiding food waste when cooking for one. Finally, a few said advances in processing enabled them to obtain reduced-calorie or low-sodium versions of foods they enjoyed.

Limited Interest in Food Origins, and Limited Trust in the Modern Food System

Many interviewees like shopping at farmers' markets, but none indicated they valued these markets for the chance to learn about the origins of their food; rather, they appreciated the food's freshness. Many expressed past or current preferences for particular farmers market vendors, 
markets, or stores, often because they regarded the food as relatively fresh and thus trustworthy. This freshness was linked to the trustworthiness of a known seller rather than a trustworthy farm. Problems with food quality were viewed as systemic and there was generally not a sense that knowing the food's origins would increase trustworthiness. A few also expressed mistrust of government oversight of the food system, for example: "This so-called watchdog called the FDA isn't up to it. It doesn't make sense." (\#5) With the exception of those who grew their own food, interviewees had little specific knowledge of where their food originated, either today or in their childhoods. Nor did they seem concerned. For example: "How would I know where it was grown at? ... All I know is I could go to the store and get it." (\#21)

Interviewees often expressed mistrust of store or food company business practices. Several thought their neighborhoods had lower quality foods than those "farther out," such as in Baltimore County, and voiced concerns that retailers were motivated more by greed than by serving customers properly. Some noted stores they would not patronize due to poor food quality or unsanitary conditions:

They giving us poor choice meats and things and go and charge us like its high price. And people my age know the difference, or they better know the difference. (\#26)

"People need to stop being so greedy, and trying to sell you defective food, food that has been in the market too long. The expiration date has passed, and they expect you to buy it. They are so greedy over money. (\#5)

Interestingly, while such discussions might seem to be "about" food safety, food safety concerns were rarely discussed directly, and interviewees did not indicate worries about foodborne illness. Indeed, several stated they thought the overall food supply was safe. Though food safety risks were objectively far higher during their youths than today, no respondent mentioned past concerns about foodborne illness or a change in food safety over time.

\section{Top Priorities for Food System Change}

Interviewees were asked to identify their top priority changes for improving the city's food system, including themes covered in our companion analyses, such as access and cost. Table 3 presents responses from 17 interviewees, including four who indicated two top priorities. Other interviewees did not clearly identify top priorities. The last column indicates priorities about which speakers spoke passionately, separate from the question about their top concerns. This column demonstrates the primacy of additives and food freshness among interviewee concerns, even compared to issues such as cost and access. 
Table 3

Most Important Priorities for Improving Baltimore’s Food System

\begin{tabular}{|l|l|l|}
\hline Priority & Top priority (\#) & Other mention (\#) \\
\hline $\begin{array}{l}\text { Address additives/processed foods, and } \\
\text { foods that are less natural or fresh }\end{array}$ & 6 & 4 \\
\hline Reduce food cost & 5 & 0 \\
\hline Improve access & 3 & 3 \\
\hline Address greed by those in the food industry & 3 & 0 \\
\hline Reduce fast food use/availability & 2 & 0 \\
\hline Return to old ways generally & 1 & 0 \\
\hline Improve food taste & 1 & 0 \\
\hline Increase nutrition education & 0 & 3 \\
\hline
\end{tabular}

\section{Discussion}

Reflection on Oral History as Pedagogy and Relevance for Other Institutions. This project provides a case study of the use of oral history to enhance student education. A key goal in the Baltimore Food Systems class is to bring the challenges and opportunities of an urban food system alive for students. We seek multiple opportunities for engagement, including tours, discussions with guests, shopping in community-based stores, and service-learning projects.

Oral history has many benefits for education. It gets students out of the classroom and contributes an additional dimension to learning by encouraging them to have in-depth conversations with real people about issues meaningful to them. Interviews thus help bridge the cultural divide between local low-income older adults and graduate students who have often come to the city only for their degree programs, and who commonly have middle and upper middle class backgrounds. It also reminds students that in efforts to make change, there is no substitute for talking directly with those who may be affected, including seeking out those who are often ignored. The project further benefits students by advancing their skills in interviewing, listening, qualitative research, teamwork, and research ethics. Over the years, both students and older adults have told us how much they valued this experience. As such, the project could contribute to a more positive perception of the university among community members. Finally, and as evidenced by this study, oral history projects can also generate valuable data for dissemination and the furthering of scholarly and public understanding of often marginalized voices.

The method presents several challenges. First, sending students out to perform oral history interviews involves a level of trust in their respectfulness, appropriateness and capabilities. It is usually not possible at the time of class planning to know what the students will be like, and even with known students, problems can occur. For example, one year with a different oral history assignment, we received feedback that a student had been inattentive during the interview, insulting the interviewee. The situation turned into an opportunity for student learning, and the interviewee appreciated we took her concern seriously. We encourage interviewees to let us 
know of any concerns both through the site contact and the consent form. Another challenge lies in building adequate interview skills in a course with a different focus. The skill of avoiding leading questions has been especially challenging to our students. We address this with longer practice opportunities during training. Lastly, there is the concern about what messages students take away from the experience. Precisely because the personal stories learned through oral histories can be so powerful for students, it is important to remind them that the comments of their interviewees may not be generalizable.

On the logistical side, given our interest in the students finding local lower income older adults to speak with for this assignment, we felt it important to arrange the contacts for them. It can take some effort to identify and establish a relationship with a person having the right connections and interest in facilitating the effort. Logistics of scheduling interviews may also be complicated. In other oral history assignments we have given, such as with family members and schoolteachers, it was easier to find interviewees and students, since they had already developed their own connections.

\section{Discussion of Findings}

This study focused on the following questions: (a) how do the interviewed older adults describe food system changes since their childhood? (b) how do they describe today's food system? (c) how are their current dietary attitudes and behaviors rooted in past experiences? Finally, (d) what do they see as priorities for food system change in Baltimore? We believe this is the first study examining older adults' views of food system change or perceptions of today's food system.

Overall, the older adults described a dramatic shift from a food system they viewed as relatively natural, healthy, and communal, to one they perceive as providing food lacking in freshness, with poorer taste, replete with additives, and that enables people to avoid home cooking (which they see as healthier than eating prepared and processed foods). Among the most frequently reported changes was a decline in food flavor. Many interviewees described mistrust of food producers, processors, and purveyors today, in contrast to a seemingly unquestioned trust in the past. Not all food system shifts were viewed unfavorably. In particular, some valued the opportunity to avoid or reduce unwanted time spent on food preparation and to purchase packaged foods in small portions or formulated with benefits such as reduced sodium.

The older adults generally recognized the social changes that have contributed to today's food system, and some questioned whether it is possible to go backward toward the food system of their childhoods. Yet, their priority list essentially reflects a desire to, at minimum, incorporate valued qualities of their childhood food system into a future food system.

Older Adults and the Flavor of Modern Food. Might the ubiquitous reports of changed food flavor be rooted simply in the older adults' altered senses of taste with age? Although sense of smell and taste may decline with age in some people, particularly those in poorer health, (Sulmont-Rossé et al., 2015), we believe for two reasons this is not the sole explanation for the results of this study. First, there is objective support the changes these older adults perceive. Studies document differences in flavor as foods age (Gray, Gomaa, \& Buckley, 1996; Kader, 2008), as well as for meats and dairy produced from pastured animals versus others (Urbach, 
1990; Priolo, Micol, \& Agabriel, 2001). Additionally, cultivar selection has shifted over time from those chosen for flavor or nutrition, to those that can produce the highest yield or that are most resilient to the time and physical requirements of the modern food distribution system (Davis, Epp, \& Riordan, 2004). Second, it is notable that the older adults focused much of their discussion of changed food taste on meats, seconded by fruits; if their senses of taste had changed, presumably this would affect their perceptions of all foods.

Preferences for Freshness and Naturalness. Today's food system is dominated by processed and prepared foods, particularly in low-income areas such as the Baltimore neighborhood where these older adults live. Such foods have often been formulated for palatability, with extensive taste testing - and many consumers find them difficult to resist (Kessler, 2010). It is notable, then, that although the older adults valued some of the convenience attributes of these foods, they generally did not indicate they preferred processed foods to fresh and home-cooked foods based on flavor.

The preference for food that is fresh, natural, and home-cooked may have multiple roots. First, there is personal nostalgia and the lifelong norms and preferences shaped by childhood diets. To date, only a few social science studies have examined older adults' food preferences, attitudes, and behaviors (Koehler \& Leonhaeuser, 2008; Song et al., 2014; McKie, MacInnes, Hendry, Donald, \& Peace, 2000; Monturo \& Strumpf, 2014; Smith, Kromm, Brown, \& Klassen, 2012; Falk, Bisogni, \& Sobal, 1996). Resonating with our findings, those studies commonly emphasize the importance of childhood in establishing lifelong approaches to food, and in developing ideals for eating patterns. It is notable that as our interviewees idealized the Southern cooking of their childhoods, none mentioned the high fat and salt content as a potential negative. Rather, such cooking was seen as beneficial to health because the food was fresh and home-cooked. Some said they had had to give up some traditional foods they loved due to fat and salt content - but these discussions were never linked to questioning childhood diets, perhaps because resultant health conditions were not evident.

Cultural nostalgia is another contributor to interviewees' preferences for fresh, home-cooked foods. Biltekoff (2010) writes "our reverence for nature and things that seem natural is closely connected with a related belief that life was healthier and more wholesome during a 'golden age' in which people lived on the land in rural or farm areas, worked hard, and ate hearty meals that were cooked by a devoted mother and enjoyed at the family table." These associations with naturalness came through strongly in our interviews. It may be that, in being linked with nostalgia, such cultural views might be stronger in older adults than in others. Indeed, it is possible these historically-focused interviews unintentionally primed interviewees toward personal and cultural nostalgia and thus toward such associations.

Third, rural roots may have affected this preference for many of those who grew up eating fresh and natural foods from farms, gardens, and hunting. Beyond personal nostalgia, the connection may also have been conceptual, as food choices can reflect identity. Southerners in Baltimore and other Northern cities experienced much pressure to assimilate. Some, mostly from the middle class, did assimilate, but for many Southerners (and presumably others from rural areas as well), their rural roots became a point of identity and pride (Zeiderman, 2006). For them and their children, an affinity for fresh foods, associated with rural farms and gardens, might become 
part of their identity. At a deeper conceptual level, Zeiderman quotes Williams (1973): "The pull of the idea of the country is towards old ways, human ways, natural ways."

A fourth reason for the interest in freshness and naturalness is that these qualities are associated with health, both by nutritionists and in popular discourse. Similar to our findings, in a qualitative study of healthy food perceptions among African Americans of diverse ages, about a third of 33 participants indicated organic and "natural" foods are healthy, and about a sixth expressed the complementary idea that "chemicals," "artificial things," and "preservatives and additives" are unhealthy (Lucan, Barg, Karasz, Palmer, \& Long, 2012). By contrast, many consumers view technology in food as 'unnatural' and 'artificial.'

Trust in the Food System. The interviewees exhibited substantial mistrust of food producers, processors, and sellers in today's food system. This mistrust seemed to be rooted primarily in the idea that businesses would prioritize profits over flavor, nutrition, or safety. As reviewed by Zachmann and Ostby (2011), nearly all the academic literature on trust in food focuses on concern about illness risk. While in this older population illness and the other possible impacts were certainly risks, the underlying emphasis was more about being wronged. The emotion underlying the mistrust was more frustration or anger than fear. A similar attitude was identified in a group of Scottish older adults (McKie, MacInnes, Hendry, Donald, \& Peace, 2000.)

Several factors could contribute to this mistrust. First, trust is relatively fragile and can be damaged more easily than built (Slovic, 1993). Negative focusing events including food safety scares receive more media attention and notice, and are given greater weight, than positive events (Slovic, 1999). Indeed, recall of food safety events is a top determinant of consumer trust in food, although recall and concern fade with time (de Jonge, Van Trijp, Renes, \& Frewer, 2010). Many consumers also distrust technology use in food production, seeing it as "unnatural" (Knox, 2000; Lusk, Roosen, \& Bieberstein, 2014). Risk perception is further affected by many factors including a person's relative social position, with women and minorities perceiving greater risk than white men (Slovic, 1999).

There is extensive evidence of racial and ethnic differentials in trust levels, commonly attributed to historical and ongoing discrimination experiences (Smith, 2010; Taylor, Funk, \& Clark, 2007). Experience of neighborhood disorder can further affect trust of a "generalized other," both directly and because it affects feelings of powerlessness (Smith, 2010; Taylor et al., 2007). Further contribution to mistrust occurs through direct experience of bias, as well as parental preparation for bias. Some studies focus specifically on trust in businesses; however, there is only limited demographic segmentation within such studies and little evidence to date of trust differentials by race (Adams, Highhouse, \& Zicker, 2010; Lang, 2013).

More specific to trust of food, one study among low-income consumers identified widespread concern about risks generated throughout the food system (Webber, Sobal, \& Dollahite, 2010; Webber \& Dollahite, 2008). As with the overall trust literature, there are relatively few studies of trust in food segmented by demographics. Particularly relevant here, Knight and Warland (2004) examined sociodemographic variation in consumer concerns about multiple types of food safety risk. They found that African Americans and those over age 65 held greater concerns about all types of risk than did others, though the relationships were not always statistically significant. 
The authors suggested these groups may perceive themselves as facing greater vulnerability to hazards than others - in the case of the elderly due to their age, and African Americans due to discrimination. Correspondingly, this sense of risk could be linked to a sense of control; these populations and those in our interviews may have relatively little control over the foods they eat and hazards therein.

Strengths/Limitations

We discussed the strengths and limitations of the oral history method above. This project has several additional strengths. It is the first study to examine older adults' perceptions of the food system and of food system change. The qualitative data collection and grounded theory methods were beneficial in an exploratory study, aiding in characterizing the subjects' underlying perceptions and views. Additionally, because the study incorporates data collected across three annual offerings of the course, subject responses are unlikely to be unduly influenced by issues in the news at a particular time.

There are several limitations. First, those at the senior center who chose to be interviewed may have been more interested in food and nutrition than others. As in other qualitative studies using convenience samples, it is not possible to generalize broadly about the findings and their applicability. Second, it is possible there were secular changes over the three years of the study. Third, older adults' perceptions, particularly of past food experiences, were dependent on their abilities to accurately recall those experiences. Fourth, while all of the (mostly graduate student) interviewers had received training, some had taken prior coursework or had more native skill as interviewers than others.

In a few cases, interviewers asked leading questions. We sought to filter those from the data by coding them as such and excluding them from analysis. In addition, complete demographic data also was not collected due to inconsistently asked questions. Consequently, we may not have captured differences in how a person interacts with the food system based on factors such as gender, race, age, or education. We also note that while it is common in oral history work to share participants' identities because the stories are specific to their lives, for the purpose of this student assignment and ease of IRB approval, we chose to present the results anonymously. A repository of food system oral histories performed with older adults would be a valuable future project.

\section{Conclusion}

Older adults are witnesses to history, and they have important insights to share. This study provides a chance to listen to one group of them and an example of oral history as a class assignment. While some might assume the main concern among these primarily low-income older adults would be food prices, interviewees also reported strong concerns about freshness and additives, mistrust of food producers and sellers, and an overall dismay about the state of the food system being passed on to their grandchildren.

Interviewees described priorities for food system change that, importantly, dovetail with many of the priorities embraced by food system reform advocates. While we have considered a number of 
motivations for the perspectives of older adults, it is important to note many of these views are shared by a growing segment of the U.S. population. Interventions to improve access to farmfresh produce, such as the USDA Senior Farmers Market Nutrition Program and programs to support price reductions in fresh and unprocessed foods, could go a long way toward addressing some of these older adults' largest frustrations. Additionally, improved governmental investment in oversight of both producers and retailers might also be valuable in responding to the older adults' concerns and in reducing the extent of mistrust.

Older adults' experiences provide valuable knowledge of food-systems change. Their insights are tied to direct experiences with another type of food system, one that shares qualities with the food system many advocates would like to see. Having lived through those times, they also recognize limitations of the food system of their childhoods, including gender roles and time required for food preparation. Drawing out this knowledge through interviews enabled students to connect with and learn from the experiences of a different generation, and gain a fresh perspective on the vast changes our food system has undergone in the last few decades. This is a clear asset to the education of public health students who will in many cases work to shape policy and programs upon graduation. Older adults, in turn, told the interviewers they enjoyed sharing their experiences with a younger generation. By engaging in oral histories with older adults, educators, interventionists, and other advocates can ensure that they are recognized as valued and important contributors to systems change.

\section{References}

Abusabha, R., Namjoshi, D., \& Klein, A. (2011). Increasing access and affordability of produce improves perceived consumption of vegetables in low income seniors. Journal of the American Dietetic Association 111, 1549-1555. http://dx.doi.org/10.1016/j.jada.2011.07.003

Adams, J. E., Highhouse, S., \& Zicker, M.J. (2010). Understanding general distrust of corporations. Corporate Reputation Review 13(1), 38-51. http://dx.doi.org/10.1057/crr.2010.6

Baltimore City Health Department. (2011, December). Neighborhood health profiles. Retrieved from http://health.baltimorecity.gov/neighborhoods/neighborhood-health-profile-reports

Biltekoff, C. (2010). Consumer response: The paradoxes of food and health. Annals of the New York Academy of Sciences 1190, 174-178. http://dx.doi.org/10.1111/j.1749-6632.2009.05268.x

Buczynski A, Freishtat H, \& Buzogany S. (2015.) Mapping Baltimore city's food environment: 2015 Report. Baltimore Food Policy Initiative and Johns Hopkins Center for a Livable Future.

Cavender G. (2015) Food Processing and Packaging. In: R.A. Neff. (ed.) Introduction to the US Food System. 2015. Wiley-Jossey Bass: San Francisco.

Church, J. \& Stewart, K. (2013, February 26). Average food prices: A snapshot of how much has changed over a century. Retrieved from http://www.bls.gov/opub/btn/volume-2/average-foodprices-a-snapshot-of-how-much-has-changed-over-a-century.htm 
Davis, D. R., Epp, M.D., \& Riordan, HID. (2004). Changes in USDA food composition data for 43 garden crops, 1950 to 1999. Journal of the American College of Nutrition 23(6), 669-682. http://dx.doi.org/10.1080/07315724.2004.10719409

de Jonge, J., Van Trijp, H., Renes, R.J, \& Frewer, L.J. (2010). Consumer confidence in the safety of food and newspaper coverage of food safety issues: A longitudinal perspective. Risk Analysis 30(1), 125-142. http://dx.doi.org/10.1111/j.1539-6924.2009.01320.x

Donald C.G. \& Tribbey R. (2002) Oral history as teacher: A case study in public administration. Journal of Public Affairs Education, 8(1), 71-81. http://www.jstor.org/stable/40215552

Eisenhauer, E. (2001). In poor health: Supermarket redlining and urban nutrition. GeoJournal 5(2), 125-133. http://dx.doi.org/10.1023/A:1015772503007

Falk, L.W., Bisogni, C.A., \& Sobal, J. (1996). Food choice processes of older adults: A qualitative investigation. Journal of Nutrition Education 28(5), 257-265.

http://dx.doi.org/10.1016/s0022-3182(96)70098-5

Gittelsohn, J., Franceschini, M., Rasooly, I.R., Rise, A.V., Ho, L.S., Pavlovich, W...Frick, K.D. (2008). Understanding the food environment in a low-income urban setting: Implications for food store interventions. Journal of Hunger \& Environmental Nutrition 2(2), 33. http://dx.doi.org/10.1080/19320240801891438

Gray, J. I., Gomaa, E.A., \& Buckley, D.J. (1996). Oxidative quality and shelf life of meats. Meat Science 43(Suppl 1), 111-123. http://dx.doi.org/10.1016/0309-1740(96)00059-9

Johnson, D. B., Beaudoin, S., Smith, L.T., Beresford, S.A., \& LoGerfo, J.P. (2004). Increasing fruit and vegetable intake in homebound elders: The Seattle Senior Farmers Market Nutrition Pilot Program. Preventing Chronic Disease 1(1), 1-9. Retrieved from CDC Web Site: http://www.cdc.gov/pcd/issues/2004/jan/03_00010a.htm

The Johns Hopkins Center for a Livable Future. (2012). Baltimore City Food Environment Map. Retrieved from http://mdfoodsystemmap.org/2014-baltimore-city-food-access-map

Kader, A. A. (2008). Flavor quality of fruits and vegetables. Journal of the Science of Food and Agriculture 88(11), 1863-1868. http://dx.doi.org/10.1002/jsfa.3293

Kessler, D. (2010). The end of overeating: Taking control of the insatiable American appetite. New York, NY: Rodale Books.

Knight, A. \& Warland, R. (2004). The relationship between sociodemographics and concern about food safety issues. The Journal of Consumer Affairs 38(1), 107-120.

http://dx.doi.org/10.1111/j.1745-6606.2004.tb00467.x 
Knox, B. (2000). Consumer perception and understanding of risk from food. British Medical Bulletin, 56(1), 97-109. http://dx.doi.org/10.1258/0007142001903003

Koehler, J. \& Leonhaeuser, I.U. (2008). Changes in food preferences during aging. Annals of Nutrition and Metabolism, 52(Suppl 1), 15-19. http://dx.doi.org/10.1159/000115342

Kunkel, M. E., Luccia, B., \& Moore, A.C. (2003). Evaluation of the South Carolina Senior Farmers Market Nutrition Education Program. Journal of the American Dietetic Association, 103(7), 880-883. http://dx.doi.org/10.1016/s0002-8223(03)00379-1

Lang, J.T. (2013). Elements of public trust in the American food system: Experts, organizations and genetically modified food. Food Policy 41, 145-154.

http://dx.doi.org/10.1016/j.foodpol.2013.05.008

Lucan, S. C., Barg, F.K., Karasz, A., Palmer, C.S., \& Long, J.A. (2012). Concepts of healthy diet among urban, low income, African Americans. Journal of Community Health 37(4), 754-762. http://dx.doi.org/10.1007/s10900-011-9508-x

Lusk, J.L., Roosen, J., \& Bieberstein, A. (2014) Consumer acceptance of new food technologies: Causes and roots of controversies. Annual Review of Resource Economics 6, 381-405. http://dx.doi.org/10.1146/annurev-resource-100913-012735

McKie, L., MacInnes, A, Hendry, J., Donald, S., \& Peace, H. (2000). The food consumption patterns and perceptions of dietary advice of older people. Journal of Human Nutrition and Dietetics, 13(3), 173-183. http://dx.doi.org/10.1046/j.1365-277x.2000.00226.x

McLaughlin, E. \& Gomez, M. (2015) Food Distribution. In: R.A. Neff. (ed.) Introduction to the US Food System. 2015. Wiley-Jossey Bass: San Francisco.

Middleton, C. \& Smith, S. (2011). Purchasing habits of Senior Farmers Market shoppers: Utilizing the theory of planned behavior. Journal of Nutrition in Gerontology and Geriatrics, 30(3), 248-260. http://dx.doi.org/10.1080/21551197.2011.591269

Monturo, C. \& Strumpf, N.E. (2014). Food, identity, and memory among aging veterans at end of life. Journal of Hospice \& Palliative Nursing, 16(3), 143-149.

http://dx.doi.org/10.1097/njh.0000000000000030

Morland, K., Wing, S., \& Diez Roux, A.V. (2002). The contextual effect of the local food environment on residents' diets: The Atherosclerosis Risk in Communities Study. American Journal of Public Health 2(11), 1761-1768. http://dx.doi.org/10.2105/ajph.92.11.1761

Oral History Association. Oral history: Defined. Retrieved from http://www.oralhistory.org/about/do-oral-history

Oral History Association. Principles and Best Practices. October, 2009. Retrieved from www.oralhistory.org/about/principles-and-practices 
Pietila, A. (2010). Not in my neighborhood: How bigotry shaped a great American city, First Edition, Chicago, IL: Ivan R. Dee.

Priolo, A., Micol, D., \& Agabriel, J. (2001). Effects of grass feeding systems on ruminant meat colour and flavor: A review. Animal Research, 50(3), 185-200.

http://dx.doi.org/10.1051/animres:2001125

Protection of Human Subjects, 45 CFR § 46.101 (2016)

Ritchie DA. Doing oral history. (2015). $3^{\text {rd }}$ ed. New York, NY: Oxford Press.

Sitton T., Mehaffy G.L., \& Davis Jr, O.L. (1983). Oral history: A guide for teachers (and others). University of Texas Press: Austin.

Slovic, P. (1999). Trust, emotion, sex, politics, and science: Surveying the risk-assessment battlefield. Risk Analysis, 19(4), 689-701. http://dx.doi.org/10.1111/j.1539-6924.1999.tb00439.x

Slovic, P. (1993). Perceived risk, trust, and democracy. Risk Analysis, 13, 675-682. http://dx.doi.org/10.1111/j.1539-6924.1993.tb01329.x

Smith, K. C., Kromm, E.E., Brown, N.A., \& Klassen, A.C. (2012). "I come from a black-eyed pea background": The incorporation of history into women's discussions of diet and health. Ecology of Food and Nutrition, 51(1), 79-96. http://dx.doi.org/10.1080/03670244.2012.635574

Smith, L.T., Johnson, D.B., Beaudoin, S., Monsen, E.R., \& LoGerfo, J.P. (2004). Qualitative assessment of participant utilization and satisfaction with the Seattle Senior Farmers' Market Nutrition Pilot Program. Preventing Chronic Disease, 1(1), 1-11. https://www.ncbi.nlm.nih.gov/pmc/articles/PMC544529

Smith, S.S. (2010). Race and trust. Annual Review of Sociology 36, 453-475. https://doi.org/10.1146/annurev.soc.012809.102526

Song, H., Simon, J.R., \& Patel, D.U. (2014). Food preferences of older adults in Senior Nutrition Programs. Nutrition in Gerontology and Geriatrics 33(1), 55-67.

https://doi.org/10.1080/21551197.2013.875502

Sulmont-Rossé, C., Maître. I., Amand, M., Symoneaux, R., Van Wymelbeke, V., Caumon, E., Tavarès, J., \& Issanchou, S. (2015). Evidence for Different Patterns of Chemosensory Alterations in the Elderly Population: Impact of Age Versus Dependency. Chemical Senses, 40(3), 153-164. https://dx.doi.org/10.1093/chemse/bju112

Taylor, P., Funk, C., \& Clark, A. (2007) Americans and social trust: Who, where and why. Pew Research Center, Washington, DC.

U.S. Bureau of the Census. (2014, July 1). QuickFacts. Retrieved from http://quickfacts.census.gov/qfd/states/24/24510.html. 
U.S. Bureau of the Census. (1995, March 27). Population of counties by Decennial Census: 1900 to 1990. Retrieved from http://www.census.gov/population/cencounts/md190090.txt.

Urbach, G. (1990). Effect of feed on flavor in dairy foods. Journal of Dairy Science, 73(12), 3639-3650. https://doi.org/10.3168/jds.s0022-0302(90)79067-4

USDA ERS. (2016). Table 7-Food expenditures by families and individuals as a share of disposable personal income. Retrieved from http://www.ers.usda.gov/data-products/foodexpenditures.aspx.

Webber, C.B. \& Dollahite, J.S. (2008). Attitudes and behaviors of low income food heads of households toward sustainable food system concepts. Journal of Hunger \& Environmental Nutrition, 3(2-3), 186-205. https://doi.org/10.1080/19320240802243266

Webber, C.B., Sobal, J., \& Dollahite, J.S. (2010). Shopping for fruits and vegetables: Food and retail qualities of importance to low-income households at the grocery store. Appetite, 54(2), 297-303. https://doi.org/10.1016/j.appet.2009.11.015

Zachmann, K. \& Ostby, P. (2011). Food, technology and trust: An introduction. History and Technology: An International Journal, 27(1), 1-10.

https://doi.org/10.1080/07341512.2011.548970

Zeiderman, A. (2006). Ruralizing the city: The great migration and environmental rehabilitation in Baltimore, Maryland. Identities: Global Studies in Culture and Power, 13(2), 209-235. https://doi.org/10.1080/10702890600698629

\section{Author Information}

Roni Neff is an assistant professor in the Department of Environmental Health Sciences at the Johns Hopkins Bloomberg School of Public Health. She directs the Food System Sustainability and Public Health Program in the Johns Hopkins Center for a Livable Future. She co-created and continues to teach the Baltimore Food Systems course, and edited the textbook, Introduction to the US Food System: Public Health, Environment, Equity. Wiley/Jossey-Bass: 2015.

Roni A. Neff, PhD (Corresponding author)

Center for a Livable Future

Johns Hopkins Bloomberg School of Public Health

615 N. Wolfe St., Suite W7010

Baltimore, MD, 21205

E-mail: rneff1@jhu.edu

Telephone: 410-614-6027 
Linnea Laestadius is an assistant professor of Public Health Policy and Administration at the Zilber School of Public Health at the University of Wisconsin-Milwaukee. She is a former CLFLerner Fellow with the Johns Hopkins Center for a Livable Future.

Linnea I. Laestadius, $\mathrm{PhD}$

Department of Public Health Policy \& Administration

Zilber School of Public Health

University of Wisconsin-Milwaukee

$1240 \mathrm{~N} 10^{\text {th }}$ St.

Milwaukee, WI 53205

E-mail: Llaestad@uwm.edu

Telephone: 414-227-4512

Susan DiMauro is a program associate with the Sustainable Agriculture and Food Systems Funders. She is a former research assistant with the Johns Hopkins Center for a Livable Future.

Susan DiMauro

PO Box 483

Summerland, CA 93067

E-mail: susiedimauro@gmail.com

Telephone: 805-698-6154

Anne Palmer directs the Food Communities and Public Health Program at the Johns Hopkins Center for a Livable Future and is a Research Associate within the Department of Health, Behavior and Society in the Johns Hopkins Bloomberg School of Public Health. She co-created and formerly co-taught the Baltimore Food Systems course.

Anne M. Palmer, MAIA

Johns Hopkins Center for a Livable Future

Johns Hopkins Bloomberg School of Public Health

615 N. Wolfe St., Suite W7010

Baltimore, MD 21205

E-mail: apalmer6@jhu.edu

Telephone: 410-502-7577

\section{Acknowledgements}

The authors sincerely thank two groups of people who were essential to this project's completion: the older adults who contributed their time, stories and insights; and the student interviewers from the Baltimore Food Systems class, 2010-12. Those students are: Qadira Ali, Patrick Baron, Stacy Blondin, Jennifer Bobb, Mia Cellucci, Yun Sang Cheah, Patricia Clay, Megan Clayton, Susan Cohen, Kristen Cooksey, Michael Crupain, Marian Dickinson, Aliza Fishbein, Laura Flamm, Laura Fox, Anne Fresia, Lauren Gibbons, Aileen Gleizer, Travis Hobart, Vanessa Hoffman, Laura Hopkins, Sarah Khasawinah, Valerie Kirby, Jesse KurtzNicholl, Diana Lee, Katherine Lee, Anthony Mazzola, Comfort Onyiah, Anna Pollock, Melissa Poulsen, Alana Ridge, Tiffany Riser, Katherine Robb, Jessica Schaeffer, Allyson Scherb, Nakiya 
Showell, Joni Sliger, Remle Stubbs-Dame, Alex Tenaglio, Scott Thorpe, Arielle Traub, Rachel Trusty, John Tyler, Gena Upshaw, Gandhi Vallaparu, Jocelyn Wagman, Eddie Yuxuan Wang, Andrew Wilbur, Ellen Wilk, Charissa Williar, Rachel Yong, and Anthony Zei. We also thank the staff of the senior center for arrangements, and Erin Biehl for her edits. 